\title{
The Amplification and Integration of Near-Death and Other Exceptional Human Experiences by the Larger Cultural Context: An Autobiographical Case
}

\author{
Rhea A. White \\ Exceptional Human Experience Network, \\ New Bern, NC
}

ABSTRACT: Although I became a parapsychologist in part to help me understand the near-death experience (NDE) I had in 1952 as an undergraduate, it was not until 1990 that I began to integrate my NDE into my life. Doing so alerted me to the role the larger cultural context plays in regard to NDEs and other exceptional human experiences (EHEs). I propose not only that we need to draw on cultural resources to amplify the meaning of our exceptional human experiences, but that EHEs themselves carry the seeds of cultural change.

In 1952 I had a near-death experience (NDE), though that term, of course, would not be coined for many years to come. Initially it changed the course of my life drastically, and it continues to do so, especially since 1990 or so, when I finally made what I experienced

Rhea White is founder and director of the Exceptional Human Experience Network (formerly the Parapsychology Sources of Information Center) and editor of the Journal of the American Society for Psychical Research, Exceptional Human Experience, and $E H E$ News. She would like to express her appreciation for the comments and criticisms offered by Patric Giesler, David Hess, and Steve Rosen on an earlier version of this paper. Reprint requests should be sent to Ms. White at the EHE Network, 414 Rockledge Road, New Bern, NC 28562. 
in the NDE the touchstone of my life, deciding to elaborate on it and live from it as fully as possible before I came to my real death, whenever that may be.

I did not have a "full-blown" NDE, yet what I experienced when I nearly died has influenced my life more than anything else. My near-death experience occurred when I was a junior in college and had driven my 1936 Ford from Penn State to Syracuse University to pick up a friend whose car was being repaired. He was to be my guest at a big weekend at Penn State. A terrible driving snowstorm developed. Visibility was almost nil as we started back south. There is a long hill as one leaves Syracuse, and try as I might, I could not get to the top. I was not the only one. Both sides of the road were lined with stranded cars. My friend asked me if I'd like him to try, and although my father had told me never to let anyone else drive my car, I answered fatefully, "Well, we'll never get there with me driving!" So we switched. My friend Stu was a very good dancer; he had a light touch on the gas pedal. He got us over the hill and we continued, going about 15 miles per hour. Then, out of the swirling snow ahead came a coal truck. As it approached it began to skid toward us.

The next thing I knew I was up in space, or so it seemed, as if looking down on the Eastern seaboard, pinpointing State College, PA, which steadily receded as I rose higher. As I relinquished my fixation that we had to get there in time for the festivities, it dawned on me that this being pulled away from Earth was what it was like to die. Obviously not being able to do anything about it, I relaxed, as if leaning back into space, and then I felt the "everlasting arms" encircling and cushioning me from behind. Then it was as if a voice said to me, "Nothing that ever lived could possibly die," as if by definition. I felt a sense of living stillness, peace, wonder, pure aliveness-and then I woke up on the hood of my car, in pain, unable to move, with the sound of the metal of the car tinkling as it settled, my head turned so that I could see cars creeping along the slippery road with people inside craning their necks to look at us.

I called to Stu but got no answer. The truck driver, who as it turned out had gone for help, returned, and an ambulance arrived eventually. As I was to learn later, Stu was killed instantly when the truck totaled the car, entering the driver's side. Perhaps it was the impact of his body against mine that shielded me and pushed me up against the roof and then out the windshield, which gave way in one piece. I had 11 fractures and was in and out of a drugged state for days, 
but when I was conscious, I could sense this singing stillness. It was what I had felt when I thought I was dying. It combined a sense of deep peace with a poised expectancy, as when a child wakes up on his or her birthday. And as the days went on, I could feel myself healing, my bones knitting. This was an exceptional experience in itself, because somehow I felt I was aware of this gentle fizz of healing energy like ginger ale in my bone cells. I did not actually feel I was in the cells or could "see" inside them as some people have reported being able to do (Murphy, 1992). It was more like an "as if" experience: my conception of what was happening could only be expressed in metaphors. But something new and real had entered my life, for it was never the same again.

I have already written about in some detail how my NDE itself influenced my life and career since it occurred more than 40 years ago (White, 1992, 1994a). Here I will show how writing the present article, which itself is an aftereffect of my NDE, was made possible only by my continual need to pursue its meaning. Although this small experience is itself quite complicated, it is only one of many experiences I could give to illustrate how each exceptional human experience (EHE) gives rise to many tendrils that, as the years pass, reach out and connect with many other EHEs, one's own and those of others, all of which appear to be products of the same process and aspects of the same overarching and underlying pattern.

Because of my NDE, I became a parapsychologist in 1954. It was my first job, and it became my profession. I have spent my life trying to understand psi phenomena, the global term for extrasensory perception (ESP) and psychokinesis (PK), the main subject matter of parapsychology, because of the challenge it presents, but initially also because I felt the answer would open the door to a fuller understanding of what I experienced in my NDE. Paradoxically, although one area of parapsychology is the attempt to find empirical evidence that some aspect of the human personality survives death, I find that area one of the least interesting. I attribute this to my NDEbased conviction that there is no death, but also to the hypothesis that what survives is here, now, and always, and the best way to investigate survival is to expand and explore the limits, if any, of the living.

I cannot emphasize enough how important it is to tap the collective consciousness as much as possible regarding EHEs. It is not difficult to encounter life-depotentiating and disparaging words about them, but we must also seek out the life-potentiating narratives about them 
(see White, in press). Some of these experiences are so evanescent, fleeting, and ineffable that to incorporate them into your life you need to bring them "down to earth" and find points of connection here in your culture, as well as share them with other people; sharing them is also an essential component of integrating an NDE or other exceptional experience (White, 1993c, 1994b, 1994d, 1994e). We need language and terms in which to pinpoint and communicate what we have experienced-not only to others, but to ourselves. But often, before we can do that, we need to know of similar experiences of others and how they were able to incorporate and integrate them-or not.

Taking my NDE as an example, for many years I referred to it simply as "the accident"; I had no other way to depict this major event in my life. I even dated important occurrences in my life as having taken place before or after "the accident." But what I referred to by "the accident" was not my car being totaled or my 11 fractures, or even the awfulness of Stu dying because I consented to his driving the car, but to what I experienced when I was out of my body.

But I didn't even have the language for that, so "the accident" was the best I could do. At least "the accident" itself was an event. It had been written up in the newspapers. I wasn't even sure myself that that intangible "something" I encountered out there seemingly in space was "real," even though I was still very aware of it, especially intuitively and viscerally. But as far as understanding its import for my life, you could say it was still suspended somewhere out there in space, waiting for me to find the words and concepts to connect and integrate it into my identity and my life.

Once I was into parapsychology and exposed to the literature, I learned about "out-of-body experiences," but I associated them with "astral travel" and adopted the parapsychological explanation that a person was not really "out" even when he or she brought back veridical information. It could have been obtained by extrasensory perception (ESP), as sometimes happens in dreams.

The first bit of cultural information that encouraged me in thinking that what I had experienced was not simply my imagination was a brief note in Time magazine ("Pleasures of dying," 1972). It was about Russell Noyes' research (1972; Noyes and Kletti, 1972) on subjective aspects of "dying," including resistance followed by surrender, dissociation from the body, a sense of peace, transcendence, and glimpses of seemingly profound truths. Here was a suggestion from the scientific literature that the current Western zeitgeist's teachings about the nature of death might be wrong. Whole new possibilities were 
opening up. This was different from investigations of life after death. This had to do with experiencing immortality while alive. Thanks to Noyes, my experience was validated for the first time as existing in its own right, not as an imagining, which in a sense enabled it to take on a life of its own independent from me.

I still referred to it as "the accident," but the cultural context was soon to change that. In the meantime, I felt a singing inside, and laughter and joy, because my wondrous experience likely had a reality beyond myself with implications far beyond any I had previously guessed, not only for myself but for others-or, one could say, not only for others, but for me. For I belonged to a nebulous group of people who had experienced something similar.

Then, in 1975, Raymond Moody's Life After Life appeared, adding a new word to the Western cultural consciousness: near-death experience. I still wasn't certain that was what I had experienced, because mine did not fit the prototypical NDE Moody set forth. But at least mine was an echo of a near-death experience, which added to its verisimilitude.

Then, when the International Association for Near-Death Studies (IANDS) was founded and Anabiosis, the precursor of this Journal, was published, I joined right away. As Vital Signs appeared and the Journal of Near-Death Studies superseded Anabiosis, and the literature on NDEs began to burgeon, including books, chapters, and articles in other scholarly journals, I realized that NDEs covered a wide range of experience and it was likely that what happened during "the accident" was indeed a near-death experience. This received the "seal of approval," as it were, when I responded to a call from Bruce Greyson to participate in his ongoing near-death research involving answering many questionnaires about one's NDE over a period of time. Potential participants were asked to send an account of their experience, which I did. I was then invited to participate, and I began to refer to "the accident" as "my near-death experience," because if a near-death researcher like Greyson considered that it qualified as an NDE for his research, then that must be what it was. I now knew I belonged to the growing group of people who had had NDEs. Thanks to IANDS, it was now easy for NDErs to learn more about NDEs and to compare their experience with those of others. Being able to name your specific EHE, being able to read or hear similar experiences of others, having your EHE the subject of serious research, and to have NDEs written about in such depth and so ex- 
tensively, is of inestimable importance both to the experiencer and, potentially, to one's culture.

By means of recent cultural currents, particularly as expressed in scholarly journals, books, general interest magazines, and even the mass media, I became aware in the late 1980 s that people were reporting many different kinds of life-changing experiences, some that fit the label "parapsychological" and many that did not, such as encounters with unidentified flying objects (UFOs), glossolalia, the "extraordinary sports experience" (Murphy and White, 1995), out-of-body experiences, even crop circles. I began to ask: "What's going on here? What is the meaning of such experiences for psi?" To answer the question, I felt I needed to look at the full spectrum of experiences from a generic viewpoint, not the usual single disciplinary approach, in which near-death researchers study NDEs, students of religion study mystical experiences, psychotherapists study transformative experiences that occur in therapy, parapsychologists study psychic experiences, and so on.

The first step in looking at these experiences generically was to coin a term that would encompass all of them, and I eventually arrived at exceptional human experience, for reasons I have explained elsewhere (White, 1990, 1992, in press). I felt a need for a term that would cover all the experiences that have been called nonordinary, unusual, anomalous, primal, and paranormal. I needed such a term because I wanted to look at the full range of experiences as a group, to see if some broad observations could be made about all or at least several of them. I did not feel the existing terms were adequate because they tended to emphasize the weirdness of such experiences and thus to encourage people to think that they themselves or other experiencers were weird as well.

These experiences, which I have placed in five broad categories of psychic experiences, mystical experiences, encounter-type experiences, death-related experiences, and experiences at the upper limits of what is generally considered "normal," or "exceptional normal experiences," are not ordinary, but they are among the most important experiences, as experiences, that one can have. Their import, I believe, is primarily subjective, even if they affect the outer world, as in poltergeist manifestations, or the body, as in stigmata. Some psychologists have studied what they call "exceptional" experiences, but by this they mean rare experiences, experiences that occur only once or a few times in a lifetime, and have a significant effect on the individual, such as graduating from college, getting married, getting 
a job, earning a significant promotion, or becoming a parent. These experiences occur in connection with events that can be objectively verified. Usually the individual involved has willed that such experiences would occur and has conducted his or her life so that they would.

Exceptional human experiences, on the other hand, are spontaneous. They happen to you, usually taking you by surprise. Although they may be associated with places or events or people, the quality that makes them exceptional is very personal and subjective. They immediately confer upon the experiencer a sense of being singled out by the touch of an unseen hand (White, in press).

The second step was to try to study the various types of EHEs to see if any generalizations could be made. I have drawn up a preliminary list of 10 possibilities (White, 1993a). In an effort to explore the import of EHEs further, I have been working with my own experiences and those of others to amplify and expand on the implications of the experiences, as suggested by the experiences themselves. The tool we have been developing to do this is the EHE autobiogra$p h y$, in which people recall and record their lives solely in terms of their EHEs, trying to connect them to each other even though they may have occurred many years apart and under very different circumstances. This cannot be done in one sitting, because we have repressed most of our EHEs. It usually takes several weeks of delving into the past, retrieving experiences and then connecting them and amplifying their possible meanings (White, 1993b, 1994c, in press).

This has been very meaningful for me personally and for the individuals with whom I have worked. It has made me consider the role of the larger cultural context in dealing with EHEs: not only ways in which culture can augment EHEs but ways in which EHEs can inject new life, new symbols, and new insights into culture at large. This is the subject of the present article. In it I express some of the tentative ideas and insights I have had about EHEs, using, as always, my own NDE as a touchstone. I am especially interested in reactions from the readers of this Journal, for although I feel the ideas set forth are relevant to any type of EHE, NDEs seem to embody most fully the generalizations I am making about all EHEs.

I propose that an exceptional human experience takes place when the collective unconscious, or the Self we all are, meets the collective consciousness. This assumption is based on my experience and that of others (for example, Dhyana, 1993; Michele, 1993) and of the founders of most religions. Broadly, the term "collective consciousness" 
could be defined as any observation, idea, impression, or aspiration of every human who has ever lived; these elements of collective consciousness are publicly available through various informal or public means of communication, such as speech, the written word, tape recordings, television and other forms of the mass media, art forms, motion pictures, and any form of electronic communication. Of course, no one living at any one time could possibly draw on all the resources available because of geographic, linguistic, economic, cultural, motivational, and other personal limitations. Our awareness of the collective consciousness of humankind is usually restricted to that which our own culture makes available to us and equips us to comprehend.

The prevailing worldview of a given culture largely determines the information sources readily available, but countercultural ideas and terms can be encountered as well. Theoretically, every culture has its primary worldview and its countercultural currents, but I have been exposed only to Western culture as mediated in the last half of the $20^{\text {th }}$ century primarily in the Eastern United States, even when it comes to what I know about Eastern, South and Central American, East European, Far Eastern, and African cultures. Therefore my conception of exceptional human experience is very much tied to Western culture. It is very likely that it is not applicable to other cultures and other time periods even in the West, especially before the Europeans discovered the Western hemisphere. But given the worldview prevailing in Western culture today and the countercultural currents also circulating, the concept of exceptional human experience appears to be timely and relevant.

Modern Western culture, on the whole, is not hospitable to exceptional human experience, yet by their very nature, EHEs cannot be easily dismissed by those who have them, though many make a great effort to do so. They are "exceptional," in part, because by definition EHEs call "ordinary" reality into question. Additionally, EHEs themselves call for an explanation, as if they were a summons from the universe to the experiencers, requiring each one to give as faithful and full an account as possible of his or her unusual experience, and then to amplify upon its meaning as fully as possible-a process that may well involve a lifetime. It is likely that EHEs may be amplified and integrated indefinitely throughout the experiencer's life and even afterward, by others, as later in this paper I do with some experiences of Thomas Merton. 
Second, because they originate in the collective unconscious, which is shared by all, I hypothesize that each one is potentially as relevant to other people as to the experiencer, though of course the feeling tone and emotional impact at second and third hand cannot be experienced the same way by others. But a lot depends on who tells the story. If a poet or dramatist or artist portrays it, its effect upon others can be profound. Even a mundane brown-paper-bag account can stir others simply because the content of the experience itself resonates deeply at the same unconscious level of the reader or listener as that from which it arose in the experiencer. But the relevance of such experiences to others is also affected by their cultural background.

It is cultural background, or my interpretation of what Pierre Bourdieu (1986) called "cultural capital," that makes it possible for EHEs to be amplified and expanded. Depending on how much cultural capital, or exposure to the larger cultural context, one has, a seemingly endless number of connections can be made at the personal, social, and cultural levels. Even if the original experiencer is illiterate and does not possess a radio or television or any publication and is therefore greatly hampered in being able to amplify or elaborate on what happened, others can carry it forward-for themselves, for others, and even for the original experiencer. In our day, popular culture is much more open to the paranormal, and one is bound to have some exposure to it, although it is superficial. The interpretive level of EHEs has no limit, not only because it is potentially as wide and as deep as all the cultures of the world put together, but also, I propose, because exceptional human experiences are the means by which cultures expand and move forward (White, 1980, 1994e). Moreover, because EHEs are dynamic, they initiate a process of unfoldment for the experiencer or group that itself need not end, to the extent that the experiencer enters consciously into the process (White, 1994a, in press).

In this process, which necessarily takes a considerable period of time - certainly months and usually years-additional EHEs of the same or different types are likely to be experienced. This sets into motion a system of multiple connections, thus increasing the opportunities for connecting with other aspects of oneself, other people, and previously unperceived cultural contents. A spiral of growth is initiated, which ideally can expand throughout the individual's lifetime, changing the person in the process, so that he or she becomes more process than person and is increasingly open to the collective 
unconscious within and the collective consciousness without. As one expands inwardly in this way, one's own outer influence increases because, by means of the cultural expansion, one's possibilities of reaching others are increased. The net one casts is both larger and more finely meshed than what one had to work with in connection with the initial EHE that captured one's imagination and called for a reorientation of one's being.

In the course of following up on my own NDE, I became a student of Gerald Heard (White, 1984), who was a contemplative first, and then a science reporter, writer, and speaker. Heard (1950) wrote that human beings stand at the confluence of two infinities, the beyond that is within and the beyond that is without. Each "has the opportunity to become a reciprocating value, a hyphen, a two-flow duct between the invisible potentiality and visible actuality, 'a swinging wicket set between,/The Seen and the Unseen" (Heard, 1950, p. 57). We must become conscious of this and experience its reality, for it is our best chance to enrich our own lives and those of others with whom we come in contact and to whom we relate, and the culture into which we were born, and beyond that, other cultures and even the Earth itself. But again, this is a vast reciprocal process, and it is not separate from us: we are the "swinging wicket"-we are the process.

As is the case with many people, all my life the Earth has sung to me, quickened me to life, cradled me. In my youth, to awake to a glimpse of blue sky and evergreen outside my window, to hear the song of a phoebe or a Baltimore oriole, made me eager to start a new day simply to be alive in the midst of such glory and wonder. I was never depressed or disappointed for long by events in my personal life because the sounds and smells and sights of Earth would call me back to joy. I didn't think about it. It was an unconscious process.

In my middle years, having discovered that the "self" that felt joy was not the only component of my being, in the travail of trying to integrate other aspects of myself, I was not open to or even denied myself the experience of joy, if it would shut the door on some much less happy aspect of myself. Now, in my senior years, secure in the living knowledge that I and the Earth, and all that is of it, are one, I can again be buoyed up by its call, at the same time that my days are darkened by the shadow of destruction that hangs over us all, a shadow that we ourselves have lowered over our world. Because we are one, we are all guilty. But in our oneness also lies our 
strength, and what we have wrought we can also "rent asunder" (I pray). With the help of grace, may it be so. And the vehicle by which grace touches us is exceptional human experience.

Thanks to my NDE, I was initiated into a journey of consciously becoming aware of who we all are and why we are here, poised between the two infinities. There is no end to either one, and ultimately, they are the same. What fun it is to become conscious through all the layers of the onion self we are! What joy it is to meet ourselves in our culture, to find ourselves reflected in new ways, opening new vistas. The unconscious awareness of the wonder of being alive is awesome in itself, but becoming personally and, more importantly, culturally aware is so much more; one learns the meaning of "and all the morning stars sang together" (Job 38:7). The aim of life, it seems to me, is to meet ourselves everywhere we go in the world, and to find the world everywhere we go in ourselves. I certainly have not attained this state, but it is an endless and infinitely wonderful project in which to be engaged!

When I began many years ago there was myself "in here" and there was the world "out there," and there was not a lot of "between the two." Since that time I have become "oned" with much of what is in the world and in other people. But there can never be an end because there is no end to growth once one enters the dynamics of the spiral that an EHE, consciously cooperated with, can initiate.

Although the individual is the vehicle in which and by which the process unfolds, it is culture that carries it forward. In the past, humans carried out and experienced this process of "oneing" by becoming immersed in a very specialized cultural groove, as in the monastic life or an artistic calling. The term "oned" is probably most often associated with the anonymous author of the 14th-century mystical text, The Cloud of Unknowing (1948), who wrote that contemplation is the process by "which a soul is oned with God" (p. 1). Even within the particular cultural path each religious sect provides, increased inner experience tends to broaden the cultural end (the macrocosm) as an individual goes further within (the microcosm). Thus, Merton, for example, sought the silence of the Trappists in the cloister at Gethsemani in Tennessee. Later, at age 43, he realized, in what was an exceptional human experience, his oneness with humanity and with the world he had "left." He was standing on a street corner in Louisville, idly "people watching," when, as William Shannon (1992) described it, he 
was suddenly overwhelmed with the realization that he loved these people and that they belonged to him and he to them. This experience shattered the notion of a separate holy existence. . . . He thrilled to the glory of being quite simply a member of the human race, not separate from others, but at one with all men and women. He writes that the experience "was like waking from a dream of separateness, of spurious self-isolation in a special world, the world of renunciation and supposed holiness. The whole illusion of a separate holy existence is a dream."

In experiencing his solidarity with all those people who did not belong to his monastic family, he experienced what he had said many times, namely, that in some mysterious way his solitude belonged to them as much as to him. "I have responsibilities for it in their regard, not just in my own. I owe it to them to be alone, and when I am alone they are not 'they,' but my own self. There are no strangers!" (p. 191)

In fact, he went within himself so far that in the last part of his life he was much more catholic than Catholic, and recognized that what he had found through his Catholic culture could be found in other world religions, especially Buddhism. On his pilgrimage to Asia, toward the end of which he would die, he had a culminating vision that not only "oned" him with all religions and all cultures, but took him beyond the reach of culture; but note that it was the culture he had necessarily imbibed that allowed him to reach that pinnacle and depth, both inside and outside himself, at the Buddhist shrine of Polonnaruwa in Kandy. There he confronted the great statues of the Buddha, and

the silence of their extraordinary faces. . . . . Filled with every possibility, questioning nothing, knowing everything, projecting nothing, the peace . . . that has seen through every question without trying to discredit anyone or anything-without refutation-without establishing some other argument. (Merton, 1973, p. 233)

He wrote that this experience knocked him over, that as he looked

at these figures I was suddenly, almost forcibly, jerked clean out of the habitual, half-tied vision of things, and an inner clearness, clarity, as if exploding from the rocks themselves became evident and obvious. The queer evidence of the reclining figure. . . . The thing about all this is that there is no puzzle, no problem, and really no "mystery." All problems are resolved and everything is clear, simply because what matters is clear. The rock, all matter, all life, is charged with dharmakaya . . . everything is emptiness and everything is compassion. (Merton, 1973, pp. 233-234) 
For him (and to an extent for me, and I hope for any reader of his words as well), this was a major exceptional human experience. Of it he wrote:

I don't know when in my life I have ever had such a sense of beauty and spiritual validity running together in one aesthetic illumination. ... I know I have seen what I was obscurely looking for. (Merton, 1973, p. 234)

This experience of Merton's was occasioned by his purposeful visit to a religious shrine, but often EHEs of profound inner significance are triggered spontaneously by objective events, some of which are made possible by our expanding technology. An excellent example of this is the overview effect induced in many astronauts as a result of viewing the Earth from outer space. Frank White coined the term "overview effect" for this particular type of EHE and has written a book about it by that title (White, 1987). He quoted many examples, including that of astronaut Russell Schweickert, who had a transforming experience during his orbital flight, followed by a second experience that occurred during a mission outside his space vehicle. He had recognized his identity with Earth while viewing it from within his space vehicle. When he was working outside the vehicle, he had the following unexpected experience:

You're no longer inside something with a window, looking out at a picture. Now you're out there and there are no frames, there are no limits, there are no boundaries. . . And there's not a sound. There's a silence the depth of which you've never experienced before, and that silence contrasts so markedly with the scenery you're seeing and the speed with which you know you're moving. (White, 1987, p. 12)

Every time I read the foregoing passage, I am transported back to my NDE: being "out there" with no frames, no limits, no boundaries, and the depth of the silence. I have been "hit" by a similar silence twice that I can recall. These experiences were probably so striking and memorable because they were reminiscent of my NDE. One occurred in 1954, when I stood on the brink of the Grand Canyon. The view, of course, was awesome. But what struck me most was the silence, which was almost palpable. It instantly recalled me to the ambiance of my NDE. The second was starting down a stairway built against a high cliff above Long Island Sound. A few steps down, with the cliffside behind to screen out sounds from above, I was struck almost physically by the silence I encountered in front 
of me. Looking down at the water sliding silently below, I was back again in the atmosphere of my NDE. I did not want to leave, or even move. I just wanted to stand there, transfixed by that magnificent silence that echoed a still deeper silence, one deep within us all.

Schweickert continued:

You know very well at that moment, and it comes through to you so powerfully that you're the sensing element for man. You look down and see the surface of that globe that you've lived on all this time, and you know all those people down there and they are like you, they are you-and somehow you represent them. . .

And when you come back there's a difference in the world now. There's a difference in that relationship between you and that planet and you and all those other forms of life on that planet, because you've had that kind of experience. It's a difference and it's so precious. And all through this I've used the word you because it's not me, it's not Dave Scott, it's not Dick Gordon, Pete Conrad, John Glenn-it's you, it's we.

It's Life that's had that experience. (White, 1987, pp. 12-13)

Another astronaut, Jeff Hoffman, cited an unidentified poem by a mountain climber that depicts the long-term influence of the overview effect, but one could say the same for any EHE:

You cannot stay on the summit forever; you have to come down again. So why bother . . . ? Just this: What is above knows what is below, but what is below does not know what is above.

One climbs, one sees; one descends, one sees no longer, but one has seen. There is an art of conducting oneself in the lower regions by the memory of what one saw higher up. When we can no longer see, we can at least still know. (White, 1987, p. 24)

It is my thesis that the noetic experience of the mountaineers, the astronauts, the NDErs-in fact, all exceptional human experiencers-is not simply theirs to recall; it is everyone's, and not in a secondary sense. Once one human has experienced it in the depths of his or her being, we have all experienced it, and not only humans, but life itself, as Schweickert so movingly expressed it, and even beyond that, I believe, Earth itself.

I believe at one time or another everyone has an exceptional experience, his or her own unique inscape, a term first used by the poet Gerard Manley Hopkins (1868/1959, p. 129) for each person's unique "intake" of that depth and height that is the Oneness of all. But even if they dismiss it, forget it, fear it, or even actively reject it, it is theirs nonetheless, but not just theirs. Theirs was 
the lens especially formed to capture that particular vision, but the import belongs to all. This includes the "overview effect" as well. If, for whatever reason, we have no insight of our own to sustain us, we can feed off those of others, because even as ours is theirs, theirs is ours.

I think we are on the brink, in this "global village" of ours, of being able to find projects of transcendence (White, 1992) in the midst of our very secular lives, and we can even engage in multiple projects. A project of transcendence is a long-term discipline or activity, such as a sport or other recreational challenge, a learning project, a volunteer activity, a therapeutic endeavor, or even one's vocation or regular job, that requires dedication, some form of ritual, and opportunities for transcendence, for going within or without, beyond one's previous limits. Any such project will provide many occasions when we will be able to go further inside/outside, making it possible for us to connect further, deeper, and higher with ourselves and with other aspects of culture and our world. As our vocabularies and symbol systems expand, so will we. As we meet ourselves in more "others," we will embrace more of the world. And each project of transcendence starts with an exceptional human experience. Each EHE is a key given to us that opens the door to the place in ourselves where we are consciously aware that the beyond that is within and the beyond that is without are the same.

To become conscious, we need the larger cultural surround or context. We need to know what others feel, say, think, and do, and what they have felt, said, thought, and done throughout the ages. In a sense it is like getting in touch with one's own past, one's own present, and then, as much as possible, at least the drift of one's future. An EHE occurs spontaneously, by definition. But, once it does, one begins the work of personal, social, and cultural integration of that experience. Much effort has been expended in the past to induce EHEs consciously, especially those of the mystical and psychical type, by drugs, sensory isolation, hypnosis, meditation, yoga, the arts, and various forms of body work and psychotherapy. In fact, I think it is spontaneous occurrences of such experiences that motivate people to climb mountains, sail singlehandedly around the world, form objects out of clay and rock, perform delicate intricate operations, and play professional basketball. These are all projects of transcendence, initiated by EHEs and aimed, in part, at experiencing additional EHEs.

By looking reflexively at my act of writing this paper, I can show how it reflects the process I am trying to describe: the manner in 
which an EHE can engender a ripple effect both within and without, and how in the process itself these two aspects of ourselves recognize their oneness in a manner that is both fed by and amplifies cultural vignettes, in the way a bird weaves its nest out of many different materials.

It is of great interest to me that, whereas I see much promise in the breakdown of overarching cultural paradigms, both religious and scientific, as setting the stage for major cultural expansions, in which individual indigenous groups and sects discover the center we all share by pushing their uniqueness as far as it will go, Australian sociologist Jack Schumaker (1990) saw the weakening of traditional religious views as a symptom of a faulty cultural system, which fosters mental illness. He held that "conventional religious paranormal beliefs have always been the most effective method for health-giving reality distortion," but "the present flood of unbelievable nonreligious beliefs" is "contributing to the health crisis of our times" (p. 6).

On the contrary, I suggest that the decline of traditional religious paranormal belief has rearranged the stage so that the sacred can be encountered any- and everywhere. Sacred space need no longer be set apart from the secular: it is everywhere. Global communication makes it easier than it has ever been to be able to incorporate aspects of many cultures into the design of one's personal belief system, which may contain both religious and traditionally nonreligious elements, all of them operating in the interest of a meaningful, connected life for the individual.

The process requires an individual, an EHE, and a degree of exposure to the collective consciousness. Given those ingredients, that individual's life can be symbolized as a pump that taps a well that will generate meaning not only for that person but for at least several other people with whom that person will come in contact throughout his or her life, and perhaps even beyond that to strangers, even as Merton has touched me, though he died more than 25 years ago.

That is where culture comes in. In a sense, it is not so much that the original EHE, even an NDE, is important in itself; rather, it is what one does with it, how one weaves it into one's life (White, 1993a, $1993 \mathrm{~b}, 1993 \mathrm{c}, 1994 \mathrm{a}, 1994 \mathrm{~b}, 1994 \mathrm{c}, 1994 \mathrm{~d}$, in press). I suggest that each in its own way is a call to enter an inner world. Once we are touched by one of these experiences, there is much that we can do in response to the call, but much of it is internal work. It will not be obvious to others. To the persons involved, it may seem like they are chasing a chimera, a mere ghost of a presence. But if they persist 
in trying to understand and follow up on the import of the experience, their lives will gradually be transformed. They will find, in Merton's felicitous phrase, what they had been "obscurely looking for." In fact, I suggest that what they have found, each in his or her unique way, is the new paradigm so many people, especially scientists, are seeking. I have called it the "experiential paradigm" (White, 1995), because you have to experience it before you can "know" it.

Psychic and mystical experiences are considered impractical, even by those who take them seriously, but I do not agree. I think they are among the most important experiences one can have, with implications and possible aftereffects that are planetwide in their significance. For if one looks at the cultural, as well as the personal and interpersonal, aftereffects in those cases where a person has followed the summons inherent in his or her EHE, one discovers that as understanding and identification grow, many invisible webs of connection are formed. Connections are forged within the self, which result in a better integrated personality. Connections are made effortlessly with other people. And perhaps most importantly, a profound sense of connection to all other forms of life is experienced, and beyond that, with life itself. Nor does it stop with animals and plants. A sense of unity is also experienced with the inanimate world, and beyond that, with the universe at large. With some EHEs, especially the mystical ones, the unitive sense comes with the initial experience. In the case of others, a process is initiated that will culminate in such experiences, if the individual follows up on the initiatory experience.

Why is this practical? It is practical because EHEs summon us to become more than we thought we were, more than mainstream culture generally teaches us that we can be, and as our sense of our self is transformed, so is our view of others and even of the planet. EHEs are potentially life-changing experiences. The poet Rainer Maria Rilke, writing of one such experience, indicated that its unspoken import was: "You must change your life" (1980, p. 245). Instead of following one's peers and living by the streetwise precepts of today's social world, one listens to another voice, an inner one that speaks very softly, so right away one of the first things one must do is set aside some quiet time simply to listen, intent on being led forth to the next step.

There are several steps one can take in response to an EHE, but here I want to emphasize the cultural approach. For example, in addition to meditating on the experience, one can seek out and speak 
to others who have had similar experiences, or one can seek guidance from a person who is a teacher or mentor. But it is not easy to locate fellow experiencers or competent teachers, although NDErs are a special case, thanks to the existence of IANDS. But if a special group devoted to the type of EHE you have had does not exist, I have a notion that simply to search the yellow pages to find someone or to use other normal, deliberate ways is not what is called for here. I am mindful of the adage, "When the pupil is ready, the teacher will appear."

An EHE is a call to get yourself ready. There are plenty of things you can still $d o$, but trying willfully to make something happen is not one of them. Inner guidance, as well as seemingly magical guidance coming from "outside," are what you should be alert to. But even when strange synchronicities occur or you have additional exceptional experiences, caution is in order. You cannot simply leap off the deep end, and yet eventually, that is precisely what you must do. But it has to be spontaneous, as spontaneous and outside your ego's willing as was the original call.

One way of seeking out others who have had similar experiences or learning from those who are more advanced than oneself is to take what I am calling the cultural approach. Simply put, it consists of sampling and possibly even devouring, if you are moved to do so, everything in your own culture-and even stepping beyond it to other cultures-that seems to speak to your own experience. Never mind if you do not know any person you can talk to. Let the people who have communicated precisely for one such as you come into your life. The American Heritage Dictionary (1982) gives this definition of culture: "The arts, beliefs, customs, institutions, and all other products of human work and thought created by a people or group of a particular period of time." We are moving today into a global, multicultural world that is composed of hundreds of indigenous cultures. Spurred on by inventions in electronics and communications, we have access, relatively inexpensively, to the world's cultural resources. Audiotapes, videotapes, computer bulletin boards, and now the World Wide Web, as well as literature, records, museums, movies, theater, art, and crafts make available to us the guidance of the ages regarding exceptional human experience. I had no fellow experiencer to talk to in my youth, but I had Heard, Ralph Waldo Emerson, Henry Thoreau, Walt Whitman, Evelyn Underhill, and Carl Jung. I hate to think what my life would be had I not had them; but I did, and that made all the difference. 
Once you find one author or artist who speaks to your condition, if you follow up on other authors or artists referred to by the first one, gradually you will become aware of a network that has developed of like-minded persons. Eventually there will be variations expressed or you will have new experiences that open new doors. In my own case, so many authors new to me are writing books today that I review 120 a year in the journal I publish, which is entitled Exceptional Human Experience. There are at least 200 more books that come to my attention that I order, and at least 300 more that I learn about but do not succeed in obtaining, for lack of time, energy, or money. I know many more exist beyond that, but I rest in the thought that I will read what I need and that the sample I am able to obtain and digest connects me nonetheless with those I am unable to obtain. I cannot obtain everything; in the meantime, what I have fills all the time, energy, and inner space I have, and continually leads me inward/outward, upward/downward, backward/forward in a wondrous dance of life and self.

We hear much talk of the global networks that exist in the physical world. I think they can be matched by global networks within each individual that connect and unite each of us with everyone and everything fully as much as the global networks of the outer world. And the doors to these networks within us are opened by our exceptional human experiences. Although in our prehistory humans may actually have been conscious of this unity, it has long since been lost with the opening of the proverbial Pandora's box and the cacophony created by the development of many nationalities and cultures. But the highest promise of the $21^{\text {st }}$ century lies not only along the Information Highway, but the exceptional internal byways within each one of us. This is not to belittle the tremendous potential of the Internet, which not only can connect each individual to the world, but also has great potential to enable people, through virtual reality, to have exceptional human experiences and to communicate about their experiences not just locally but planetwide. There are now sufficient cultural assets available to enable people to understand and build on their own unique and individual exceptional human experiences. Cultural amplification of our EHEs will enable us to become consciously aware of our connection to everything else. Here is how I envisage it.

To take myself as an example, although I had my NDE in 1952, I could not have written this paper even a year ago, because I had not yet read about the specific EHEs of the space explorers, with 
the exception of Edgar Mitchell's (1974) account. I had not read about Merton's two experiences. I found out about the "overview effect" because of an article I abstracted for Exceptional Human Experience, which for me serves as one means of following up on the ripple effect of my own EHEs. I found out about Merton's Polonnaruwa experience because I shared my experiences with Loretta Kelleher, a fellow librarian and a Merton devotee, who brought his experience to my attention. In following up on that experience of Merton's, I came across the account of his Louisville experience. Heard's words have echoed through my life since I had the great fortune to attend his lectures in the early $1950 \mathrm{~s}$, when I first began to try to understand the meaning of my near-death and related mystical experiences. In that same period of search I read The Cloud of Unknowing (1948), and about the process of "oneing."

In following up on my NDE, for many years Heard's writings, The Cloud of Unknowing (1948), and hundreds of other related books I read were relegated to only one room of my cultural house. My aim was to reconcile the wisdom and experience they contained with my too-stubborn daily life and that of others, but I was involved in science, where meaning, it seems, must everlastingly wait for data to pile up and finally squeak. By 1990 , my culture came to the rescue through feminist, postmodern, hermeneutic, narrative, and heuristic approaches outside my chosen field of parapsychology. At last I had found what I had been "obscurely looking for." I found these to be such abundant approaches to meaning that I stopped waiting outside the mouse hole and jumped into what I feel will one day be the mainstream of Western culture, if it is not already. In entering the science of parapsychology, my aim had been to be on the growing edge of Western thought. When I discovered that edge not only was not in parapsychology but was burgeoning elsewhere, I had no choice but to follow.

So here we have one little individual following up on one nondescript NDE-with considerable verve and energy, to be sure-but I believe that drive and energy had their origin in the NDE itself, and that it is a component of any EHE. Each one contains the energy and the direction needed to carry it forward and allow it to expand, but one must consciously cooperate with the process.

It is self-feeding if one aims to move forward. If one fails at least to try to follow up, the energy seeps away and nothing will happen. The sweet sap may even turn to vinegar and affect the experiencer's life in a negative way. Your life cannot be changed, because you have 
not given your consent. The concept of exceptional human experience for me serves as the bridge between the two infinities, between my most exceptional personal internal experiences and the vast reaches of both environment and culture, not only in the present but also in the past. In my NDE I was oned with life and with the sacred. By finally basing my life on it, I am oned with people, the environment, the Earth itself. If all this can happen to me, it can happen to anyone.

Implicit in each EHE is the special key to the hidden door opening on the best possible life for each one of us. If we don't turn the key and go through the door, our lives will be mostly humdrum and boring. How not? If we are not living with our full selves, if our lives are not imbued with meaning that connects us to life, to others, to our world, then what we are doing is chasing a shadow, not feeding on substance-because in reality we are connected, we will have what we need if we will only pay attention to our own unique message as it is expressed through our EHEs. But it is not a one-way street. One can go within to find the place that embraces the outer world, as Merton did, or one can go without, and through the transformational capacity of an EHE, find that the outer world is mirrored within, which is what happened with the astronauts, the mountain climbers, and to me in a mystical experience during contemplation, which was initiated as an aftereffect of my NDE. Indeed, I regard it as the fulfillment of my NDE, which was not full-blown. The knowledge many NDErs come back with, in my case, had to be induced by undertaking intense spiritual discipline. But it all started with my NDE.

I think that as a species we no longer need to turn to religion as such to engage in a project of transcendence. Anywhere we are moved to be or to go will do as well, if not better, because one need not adhere to the tenets of a specific religious text. We can induce and develop and expand ourselves inwardly/outwardly simply by heeding the experiences life gives us; and then by actively seeking cultural metaphors and symbols to inform and eventually transform them, we will be adding our individual increment to culture at large, that is, to the collective consciousness of our time and place. However, every religion in essence is also a project of transcendence that may answer an individual's needs. But religions are no longer the only approach to the sacred, even though they will likely remain prototypical for some time to come. All religions also provide a prime cultural source of insight and wisdom that we can draw on in seeking 
the meaning of our exceptional experiences. Spending time in cathedrals, mosques, and other traditionally holy places is likely to induce the state of consciousness that can produce key insights that would be more difficult to have in the bustle of a city. Wilderness-even being in the presence of a favorite tree or rock or animal-can also facilitate awareness and deepen consciousness.

The point is that we are all called to inscendence/transcendence, to become more than we are by interacting with and joining the world inside with the world outside. The term "inscendence" was used by Father Thomas Berry (1988/1990) as a complement to "transcendence": inscendence is the experience of going beyond previous subjective limits inwardly, whereas transcendence is the experience of going beyond previous subjective limits outwardly. The sacred is where one meets it, and that can be anywhere. That meeting is an exceptional human experience, and that experience can lead to one's own project, a project that will serve as a means by which the individual uses social relations and culture to amplify his or her experience and, ultimately, him- or herself, and in so doing, to enrich those relationships and that culture in return. The concept is not new; in ancient times, for example, it was called lila, the divine play, or the divine dance of Shiva.

What is different in our day is that this dance of the two infinities can occur on a global scale: the whole world can become conscious of its oneness, with each individual, social group, and culture working through its native ways to find that which we all are, all of us knowing it individually and together. If we don't dance, there may be no more beyond that is without for us, and we will lose the opportunity that has been building here on Earth since the first life forms were spawned. In one way or another, life reaches all of us with moments of exceptional experience. Whether we deny, repress, revile, or build on them is the most important personal-and cultural-choice we will ever have to make.

\section{References}

American heritage dictionary (2nd ed.). (1982). Boston, MA: Houghton Mifflin.

Berry, T. (1990). The dream of the earth. San Francisco, CA: Sierra Club Books. (Original work published 1988)

Bourdieu, P. (1986). The forms of capital. In J. G. Richardson (Ed.), Handbook of theory and research for the sociology of education (pp. 241-258). New York, NY: Greenwood Press. 
Cloud of unknowing, The. (1948). New York, NY: Harper/Pendle Hill.

Dhyana, I. M. G. (1993). More than me: Confessions, perceptions, and inspirations of a modern-day mystic. San Francisco, CA: Dhyana Press.

Heard, G. (1950). Is God in history? New York, NY: Harper and Brothers.

Hopkins, G. M. (1959). Journals and papers. (H. House, Ed.; completed by G. Story). Oxford, England: Oxford University Press. (Original work written in 1868)

Merton, T. (1973). The Asian journal of Thomas Merton. New York, NY: New Directions.

Michelle, C. (pseud.). (1993). Exceptional human experience 16: Mystical experiences. The experience of "All Things." Exceptional Human Experience, 11, 40-44.

Mitchell, E. D. (1974). Introduction: From outer space to inner space. . . . In E. D. Mitchell, Psychic exploration: A challenge to science (J. White, Ed.) (pp. 25-50). New York, NY: Putnam.

Moody, R. A. (1975). Life after life. St. Simons Island, GA: Mockingbird Books.

Murphy, M. (1992). The future of the body: Explorations into the further evolution of human nature. Los Angeles, CA: Tarcher.

Murphy, M., and White, R. A. (1995). In the zone: Transcendent experience in sports. New York, NY: Penguin/Arkana.

Noyes, R. (1972). The experience of dying. Psychiatry, 35, 174-184.

Noyes, R., and Kletti, R. (1972). The experience of dying from falls. Omega, 3, 45-52. Pleasures of dying. (1972, December 4). Time, 100, 62-64.

Rilke, R. M. (1980). Archaic torso of Apollo. In R. Bly (Ed.), News of the universe: Poems of twofold consciousness. San Francisco: Sierra Club Books.

Schumaker, J. F. (1990). Culture failure and nonreligious paranormal beliefs. Australian Parapsychological Review, No. 16, 6-8.

Shannon, W. H. (1992). Silent lamp: The Thomas Merton story. New York, NY: Crossroads.

White, F. (1987). The overview effect: Space exploration and human evolution. Boston, MA: Houghton Mifflin.

White, R. A. (1980). On the genesis of research hypotheses in parapsychology. Parapsychology Review, 11(1), 6-9.

White, R. A. (1984). Gerald Heard's legacy to psychical research. In M. C. Rose (Ed.), Academy of Religion and Psychical Research 1982 Annual Conference Proceedings (pp. 56-59). Bloomfield, CT. Academy of Religion and Psychical Research.

White, R. A. (1990). An experience-centered approach to parapsychology. Exceptional Human Experience, 8, 7-36.

White, R. A. (1992). Seek ye first the kingdom of heaven: What are EHEs and what can we do about them? In The ramifications and implications of exceptional human experiences: Mystical and psychical: The Academy of Religion and Psychical Research 1992 Annual Conference Proceedings (pp. 1-42). Bloomfield, CT. Academy of Religion and Psychical Research.

White, R. A. (1993a). Brief overview of exceptional human experiences. Journal of Religion and Psychical Research, 16, 2-4.

White, R. A. (1993b). From coincidence to context to connection. Journal of Religion and Psychical Research, 16, 123-125.

White, R. A. (1993c). Review essay 2: Acts of meaning by Jerome Bruner: A call to psychology and parapsychology. Exceptional Human Experience, 11, 5-13.

White, R. A. (1994a). A dynamic view of psi experience: By their fruits ye shall know them. In Exceptional human experience: Background papers (pp. 59-65). Dix Hills, NY: Exceptional Human Experience Network.

White, R. A (1994b). Exceptional human experiences as vehicles of grace: Parapsychology, faith, and the outlier mentality. In Exceptional human experience: Background papers (pp. 47-58). Dix Hills, NY: Exceptional Human Experience Network. 
White, R. A. (1994c). How to write an EHE autobiography. Exceptional Human Experience, 11(2), 132-134.

White, R. A. (1994d). Role theory and exceptional human experience. Journal of Religion and Psychical Research, 17, 74-77.

White, R. A. (1994e). The inward Olympics: On finding ways to deepen consciousness and touch the self we all are. Exceptional Human Experience, 11(2), 98-107.

White, R. A. (1995). Exceptional human experiences and the experiential paradigm. ReVision, 18(2), 18-25.

White, R. A. (In press). Dissociation, narrative, and exceptional human experiences. In S. Krippner and S. M. Powers (Eds.), Broken images, broken selves: Dissociative narratives in clinical practice. New York, NY: Brunner/Mazel. 